\title{
Prevalence, patterns, and perceived value of complementary and alternative medicine among HIV patients: a descriptive study
}

Mandreker Bahall ${ }^{1,2,3}$ (D)

\begin{abstract}
Background: Use of complementary and alternative medicine (CAM) is widespread among different patient populations despite the availability of evidence-based conventional medicine and lack of supporting evidence for the claims of most CAM types. This study explored the prevalence, patterns, and perceived value of CAM among human immunodeficiency virus (HIV) patients.

Methods: This quantitative descriptive study was conducted between November 1, 2014 and March 31, 2015 among a cross-sectional, convenience sample of attendees of the HIV clinic of a public tertiary health care institution. Face-to-face interviews using a 34-item questionnaire were conducted. Data analysis included descriptive statistics, chi-square tests, and binary logistic regression analysis.

Results: CAM was used by 113 (32.8\%) of a total of 343 HIV patients, but $<1 \%$ informed their health care providers of CAM usage. Medicinal herbs were the most common type of CAM used ( $n=110,97.3 \%)$ followed by spiritual therapy $(n=56,49.6 \%)$, including faith healing/prayer and meditation. The most used medicinal herbs were Aloe vera $(n=54,49.1 \%)$, ginger $(n=33,30.0 \%)$, and garlic $(n=23,20.9 \%)$. The most used vitamins were complex $\mathrm{B}$ vitamins $(n=70,61.9 \%)$, followed by vitamin $\mathrm{A}(n=58,51.3 \%)$, vitamin $\mathrm{E}(n=51,45.1 \%)$, and vitamin $\mathrm{D}(n=42,37$. 1\%). Most CAM users continued using conventional medicine in addition to CAM and were willing to use CAM without supervision and without informing their health care provider. Patients were generally satisfied with CAM therapy $(n=91,80.5 \%)$. The main reasons for CAM use were the desire to take control of their treatment (8.8\%) or just trying anything that could help (18.8\%). Main influences were the mass media (32.7\%) and non-hospital health personnel (19.5\%). Predictors of CAM use were being 30-50 years, married and having a secondary school education.
\end{abstract}

Conclusion: About one-third of HIV patients used CAM, but virtually none informed their healthcare provider. Medicinal herbs were the most common type of CAM, followed by spiritual therapy and vitamins. A patient's decision to use CAM was influenced for the most part by the mass media and non- hospital health care personnel.

Keywords: Complementary and alternative medicine, Human immunodeficiency virus, Medicinal herb, Satisfaction, Side effects, Spiritual therapy

\footnotetext{
Correspondence: vmandrakes@hotmail.com

${ }^{1}$ School of Medicine and Arthur Lok Jack Graduate School of Business,

University of the West Indies, St. Augustine, Trinidad and Tobago

2Department of Medicine, San Fernando General Hospital, Chancery Lane,

San Fernando, Trinidad and Tobago

Full list of author information is available at the end of the article
} 


\section{Background}

Conventional medicine (CM) has improved patient outcomes (e.g. life expectancy, quality of life, and patient satisfaction) in various diseases. However, there remain many unresolved challenges, such as inadequacy, ineffectiveness, inaccessibility, side effects, and unfulfilled patient expectations [1,2]. Many patients infected with human immunodeficiency virus (HIV), have turned to complementary and alternative medicine (CAM) [3, 4] because of its perceived claims, namely curing [5], counteracting the side effects of $\mathrm{CM}[6-8]$, providing and promoting wellness and holistic care $[6,9]$ and treating a number of irreversible and chronic conditions such as HIV infections [10]. CAM is defined as "a group of diverse medical and health care systems, practices, and products that are not generally considered part of conventional medicine" [11]. It comprises herbs, dietary supplements, meditation, biofeedback, hypnosis, acupuncture, Ayurveda, homeopathy, naturopathy, Chinese medicine, chiropractic, massage, tai chi, yoga, electromagnetic therapy, kinesiology, reiki, and qigong.

The global prevalence of CAM varies with cultures, countries, and the interpretation of CAM, ranging from $9.8 \%$ to $76.0 \%$ [12]. The prevalence of CAM has been reported to be $38 \%$ among adults in the United States [13], 51.8\% in the United Kingdom [14], and 68.9\% in Australia [15]. In Trinidad and Tobago, the prevalence of CAM is $30.4 \%$ among asthmatics (for herbal medicines) [16], 56\% among cardiac patients (for any type of CAM) [17], 24\% among diabetic patients attending chronic disease clinics (for herbs) [18]. On average, 60\% of HIV-positive individuals use CAM to treat HIVrelated health concerns in the United States $[8,19,20]$. However, no studies have explored CAM usage among HIV patients in Trinidad and Tobago.

Trinidad's traditional medicine (nonconventional indigenous medical practices) [21] and home medication/ remedies [22, 23] have been in use by Amerindians (e.g. Tainos and Kalinagos), Afro-Trinidadians, and IndoTrinidadians for centuries, and are still used in part due to the lack of available conventional health care [24] and the influence of positive testimonies and perceived benefits. Hsu et al. [25] showed that some patients with back pain feel cured with CAM, while others feel stronger, happier, livelier, and more motivated to live. Some patients also report stress relief [6]. With CM, patients benefit from improved quality of life, decreased mortality, decreased morbidity, and increased life expectancy $[26,27]$. Nonetheless, HIV patients have numerous concerns, including depression [28, 29], stress and other psychological problems [30, 31], neglect by family members [32, 33], and limited or no resources [34]. Much of patient's social [35] and spiritual needs [36] are ignored by $\mathrm{CM}$ practitioners, thus creating major gaps in patient health care [37]. Customer centredness was identified as a major indicator of quality health care by the United States Institute of Medicine [38].

HIV prevalence in Trinidad is on the rise [39] even though disease complications are decreasing [26]. Improvement of clinical outcomes is largely attributed to antiretroviral drugs [40] provided free by the Ministry of Health. Despite such benefits, some patients still seek help from CAM. This study explores the prevalence, patterns, and perceived value of CAM among HIV patients.

\section{Methods}

\section{Study design and population}

This cross-sectional study was conducted among HIV clinic attendees of San Fernando General Hospital (SFGH) between November 1, 2014 and March 31, 2015. This HIV clinic is the only public clinic servicing about half (600000) of the population of Trinidad [41]. SFGH HIV clinic attendees are males (63\%), Indo-Trinidadian (17.3\%), Afro-Trinidadian (71.2\%) and mixed descent (11.5\%), and mainly in the age groups of $21-30$ years (15.3\%), 31-40 years (31.9\%), $41-50$ years $(25.2 \%)$, and 51-60 years (17.3\%) (data from the Monthly Report of the HIV Clinic of San Fernando General Hospital, June 2016). Inclusion criteria were age $>18$ years, ability to communicate verbally, and consent to participate in the study. The desired sample size of 369 was determined to be needed in order to estimate the number of patients who used CAM (around 40\%) with a margin of error of 5\%. [42] Exclusion criteria were confusion (e.g. impairment of cognition and clarity) and inadequate memory recall (i.e. inability to give adequate past information) as assessed by the research assistant.

\section{Data collection}

The data collection instrument was previously tested and used among cardiac patients in Trinidad. [17] It is a 37-item questionnaire covering demographics (seven items), current HIV condition (five items), and various aspects of CAM usage such as types of CAM, experiences, reasons, benefits, influences, effects, consequences, sources and access to CAM (25 items). Eight independent variables were considered: sex, marital status, ethnicity, educational level, employment status, religion, religiosity, and area of residence. Categorical data included employment status (unemployed, employed, retired, and unemployed due to sickness/disability) and monthly income ( $\leq$ TT $\$ 2500$, TT\$2501-5000, TT\$5001$10,000$, and $>$ TT $\$ 10000)$. The type of CAM used was selected from a list of different types from the NCCAM, with each expanded to the specifics developed from common practices. The list of the various CAM types comprised herbal therapy (Aloe vera, Ginkgo, ginger, turmeric, etc.), spiritual therapy (faith healing, meditation, 
hypnotherapy, psychic therapy, etc.), alternative systems (Chinese medicine, Indian/Ayurveda medicine, acupuncture, homeopathy), physical therapy (chiropractice, osteopathy/bone setters, massage, manual healing), energy therapies (bio-electrics magnetics, oxygen/ozone treatment), and other therapies (bloodletting cupping, ritual sacrifice, urine therapy, folk magic/sorcery (obeah), etc.). Each question about CAM was phrased such that the patients could respond with a list of possibilities and include others that were not listed by the NCCAM. Patients were free to choose more than one option. Faceto-face interviews were conducted with consenting patients in a private consultation room by a pre-medical student.

\section{Statistical analysis}

Descriptive methods included frequency distribution tables and graphs. Inferential methods included tests of equality of proportions, chi-squared tests of association (e.g. Fisher's exact test and McNemar's test of paired proportions) between selected socio-demographic characteristics or other attribute variables and CAM use. Binary logistic regression was used to identify predictors of CAM use. All hypotheses were tested at the 5\% level of significance.

\section{Results}

A total of 343 HIV patients (response rate: 93\%) participated in the study. Four patients refused to participate without reason, and 23 patients decided not to participate for various reasons, including privacy and uncomfortable feeling. Study participants were mainly females ( $n=185,53.9 \%)$, aged $21-40$ years $(n=198,57.7 \%)$, single $(n=197,57.4 \%)$, Afro-Trinidadian $(n=178,51.9 \%)$, Christian $(n=206,60.0 \%)$, attended up to secondary school $(n=252,73.5 \%)$, and were employed during the data collection period $(n=238,69.4 \%)$. Almost half of the participants $(n=171,49.8 \%)$ reported having a monthly income of TT\$5000 or less (Table 1 ).

The internal reliability (Cronbach's alpha) was 0.981 based on non-socioeconomic factors such as attitude, practices, and knowledge. A total of 113 (32.9\%) patients answered 'Yes' to the question 'Have you used complementary and alternative medicine?, with the remaining 230 (67.1\%) answering 'No'. A comparison of selected demographic characteristics between CAM users and non-users is shown in Table 2.The two groups had similar profiles except for ethnicity and education. The percentage of users who were Indo-Trinidadians was more than double than the percentage of non-users who were Indo-Trinbagonians $(59.8 \%$ vs. $26.5 \% ; p=0.030)$. The percentage of non-users who completed only up to primary school was more than double than that of users $(17.7 \%$ vs. $8.0 \% ; p=0.015)$. The opposite was true for
Table 1 Socio-demographic characteristics of the study participants

\begin{tabular}{|c|c|c|}
\hline Characteristic & Number & Percent \\
\hline \multicolumn{3}{|l|}{ Gender } \\
\hline Male & 158 & 46.1 \\
\hline Female & 185 & 53.9 \\
\hline \multicolumn{3}{|l|}{ Age (years) } \\
\hline$<20$ & 26 & 7.6 \\
\hline $21-30$ & 95 & 27.7 \\
\hline $31-40$ & 103 & 30.0 \\
\hline $41-50$ & 90 & 26.2 \\
\hline $51-60$ & 3 & 0.9 \\
\hline$>60$ & 26 & 7.6 \\
\hline \multicolumn{3}{|l|}{ Marital status } \\
\hline Single & 197 & 57.4 \\
\hline Married & 59 & 17.2 \\
\hline Widowed & 20 & 5.8 \\
\hline Divorced & 24 & 7.0 \\
\hline Common law & 38 & 11.1 \\
\hline \multicolumn{3}{|l|}{ Ethnicity } \\
\hline Afro-Trinidadian & 178 & 51.9 \\
\hline Indo-Trinidadian & 79 & 23.0 \\
\hline Other (including mixed) & 86 & 25.1 \\
\hline \multicolumn{3}{|l|}{ Highest level of education } \\
\hline Up to primary & 50 & 14.6 \\
\hline Secondary & 252 & 73.5 \\
\hline Tertiary & 39 & 11.4 \\
\hline \multicolumn{3}{|l|}{ Employment status } \\
\hline Employed & 238 & 69.4 \\
\hline Unemployed & 105 & 30.6 \\
\hline \multicolumn{3}{|l|}{ Religion } \\
\hline Hindu & 53 & 29.7 \\
\hline Islamic & 17 & 7.9 \\
\hline Christian & 206 & 60.0 \\
\hline Other & 39 & 11.3 \\
\hline No response & 27 & 7.9 \\
\hline
\end{tabular}

users and non-users who had completed their tertiary education $(18.6 \%$ vs. $7.8 \%$; $p=0.006)$.

Of the seven demographic variables measured, middle age $31-40$ (odds ratio [OR] $0.287 ; p=0.031 ; 95 \%$ confidence interval [CI] 0.092-0.894), 41-50 (odds ratio [OR] $0.252 ; p=0.017 ; 95 \%$ confidence interval $[\mathrm{CI}] 0.082-$ 0.778), married (odds ratio [OR] 3.048; $p=0.036 ; 95 \%$ confidence interval $[\mathrm{CI}]$ 1.078-8.819), with married individuals more likely to be associated with CAM use (reference group: single), and secondary school education (OR 19.599; $p=0.014 ; 95 \%$ CI 1.836-209.248) (reference 
Table 2 Socio-demographic characteristics of CAM users and non-users

\begin{tabular}{|c|c|c|c|}
\hline Characteristic & CAM users & CAM non-users & $p$ \\
\hline \multicolumn{4}{|l|}{ Gender } \\
\hline Male & 47 (41.6) & $111(48.3)$ & 0.252 \\
\hline Female & $66(58.4)$ & $119(51.7)$ & 0.252 \\
\hline \multicolumn{4}{|l|}{ Age (years) } \\
\hline$<20$ & $5(4.4)$ & $21(9.1)$ & 0.135 \\
\hline $21-30$ & $34(30.1)$ & $61(26.5)$ & 0.522 \\
\hline $31-40$ & $40(35.4)$ & $63(27.4)$ & 0.134 \\
\hline $41-50$ & $30(26.5)$ & $60(26.1)$ & 0.927 \\
\hline $51-60$ & $0(0.0)$ & $3(1.3)$ & 0.544 \\
\hline$>60$ & $4(3.5)$ & $22(9.6)$ & 0.052 \\
\hline \multicolumn{4}{|l|}{ Marital status } \\
\hline Single & $57(50.4)$ & $140(60.9)$ & 0.081 \\
\hline Married & $20(17.7)$ & $39(17.0)$ & 0.880 \\
\hline Widowed & $10(8.8)$ & $10(4.3)$ & 0.139 \\
\hline Divorced & $7(6.2)$ & $17(7.4)$ & 0.823 \\
\hline Common law & $18(15.9)$ & $20(8.7)$ & 0.066 \\
\hline \multicolumn{4}{|l|}{ Ethnicity } \\
\hline Afro-Trinidadian & $62(54.9)$ & $116(50.4)$ & 0.491 \\
\hline Indo-Trinidadian & $18(59.8)$ & $61(26.5)$ & 0.030 \\
\hline Other & $33(29.2)$ & $53(23.0)$ & 0.234 \\
\hline \multicolumn{4}{|l|}{ Employment status } \\
\hline Unemployed & $83(73.5)$ & $155(67.4)$ & 0.265 \\
\hline Employed & $30(26.5)$ & 75 (32.6) & 0.265 \\
\hline \multicolumn{4}{|l|}{ Education level } \\
\hline Primary school & $9(8.0)$ & $41(17.8)$ & 0.015 \\
\hline Secondary school & $82(72.6)$ & $170(73.9)$ & 0.509 \\
\hline Tertiary & $21(18.6)$ & $18(7.8)$ & 0.006 \\
\hline
\end{tabular}

CAM complementary and alternative medicine

Data are the mean number (percentage)

group: primary school) were the only useful predictors of the likelihood of using CAM among HIV patients (Table 3).

Medicinal herbs were the most common type of CAM used $(n=110,97.3 \%)$, followed by spiritual therapy $(n=56,49.6 \%)$ (Fig. 1). Aloe barbadensis Miller (Aloe vera) $(n=54,49.1 \%)$ was the most commonly used medicinal herb, followed by Zingiber officinale (ginger) ( $n=33,29.2 \%)$, and Allium sativum (garlic) $(n=23$, 20.4\%) (Table 4). Only 2 patients (1.8\%) used medicinal teas. Complex B vitamins were the most commonly used supplement $(n=69,61.1 \%)$, followed by vitamin A $(n=58$, $51.3 \%)$, vitamin $\mathrm{E}(n=51,45.1 \%)$, and vitamin $\mathrm{D}(n=42$, $37.2 \%)$. Almost half of CAM users $(n=56,49.6 \%)$ resorted to spiritual therapy, all of whom sought faith healing/prayer $(n=56,100 \%)$ and $13(23.2 \%)$ practised meditation. Two (1.8\%) CAM users used Chinese medicine; none used Indian/Ayurveda medicine; 1 (0.9\%) used acupuncture; and
Table 3 Binary Logistic Regression for CAM use among patients

\begin{tabular}{|c|c|c|c|c|}
\hline \multirow[t]{2}{*}{ Variable } & \multirow[t]{2}{*}{ OR } & \multirow[t]{2}{*}{$p$} & \multicolumn{2}{|l|}{$95 \% \mathrm{Cl}$} \\
\hline & & & Lower & Upper \\
\hline \multicolumn{5}{|l|}{ Age } \\
\hline Under 20 & 1 & & & \\
\hline $21-30$ & 0.672 & 0.588 & 0.160 & 2.828 \\
\hline $31-40$ & 0.287 & 0.031 & 0.092 & 0.894 \\
\hline $41-50$ & 0.252 & 0.017 & 0.082 & 0.778 \\
\hline Over 50 & 0.320 & 0.051 & 0.102 & 1.003 \\
\hline \multicolumn{5}{|l|}{ Sex } \\
\hline Male & 1 & & & \\
\hline Female & 1.667 & 0.141 & 0.842 & 3.340 \\
\hline \multicolumn{5}{|l|}{ Marital status } \\
\hline Single & 1 & & & \\
\hline Married & 3.048 & 0.036 & 1.078 & 8.819 \\
\hline Widowed & 2.622 & 0.114 & 0.793 & 8.669 \\
\hline Divorced/Separated & 1.576 & 0.589 & 0.303 & 8.186 \\
\hline Common Law & 2.715 & 0.215 & 0.560 & 13.157 \\
\hline \multicolumn{5}{|l|}{ Ethnicity } \\
\hline Afro-Trinidadian & 1 & & & \\
\hline Indo-Trinidadian & 0.865 & 0.708 & 0.404 & 1.85 \\
\hline Mixed & 3.913 & 0.062 & 0.933 & 16.412 \\
\hline \multicolumn{5}{|l|}{ Education } \\
\hline Primary school & 1 & & & \\
\hline Secondary school & 19.599 & 0.014 & 1.836 & 209.248 \\
\hline Tertiary & 1.870 & 0.216 & 0.694 & 5.041 \\
\hline \multicolumn{5}{|l|}{ Income (\$TT) } \\
\hline$<\$ 2500$ & 1 & & & \\
\hline$\$ 2501-\$ 5000$ & 1.536 & 0.463 & 0.488 & 4.836 \\
\hline Over $\$ 5000$ & 1.503 & 0.320 & 0.674 & 3.351 \\
\hline \multicolumn{5}{|l|}{ Religion } \\
\hline Islam & 1 & & & \\
\hline Hindu & 0.643 & 0.566 & 0.142 & 2.904 \\
\hline Baptist & 0.537 & 0.473 & 0.099 & 2.93 \\
\hline Anglican & 2.797 & 0.071 & 0.914 & 8.554 \\
\hline Roman Catholic & 2.17 & 0.187 & 0.687 & 6.852 \\
\hline Other & 1.33 & 0.636 & 0.409 & 4.329 \\
\hline
\end{tabular}

none used homeopathy. Ten (8.8\%) CAM users reported that they had abandoned CM for CAM in the past (1 before $\mathrm{CM}$ was completed, 5 after $\mathrm{CM}$ was completed, and 4 while $\mathrm{CM}$ was being used). When asked how frequently they substituted their CM treatment, 100 (88.5\%) patients said they never do (i.e. they combined CAM with CM), while the remaining 13 responded 'often/sometimes/occasionally' in the ratio $2 / 5 / 6$.

Only 17 (15.0\%) patients claimed to have received any specific benefit from CAM. However, when asked to list 


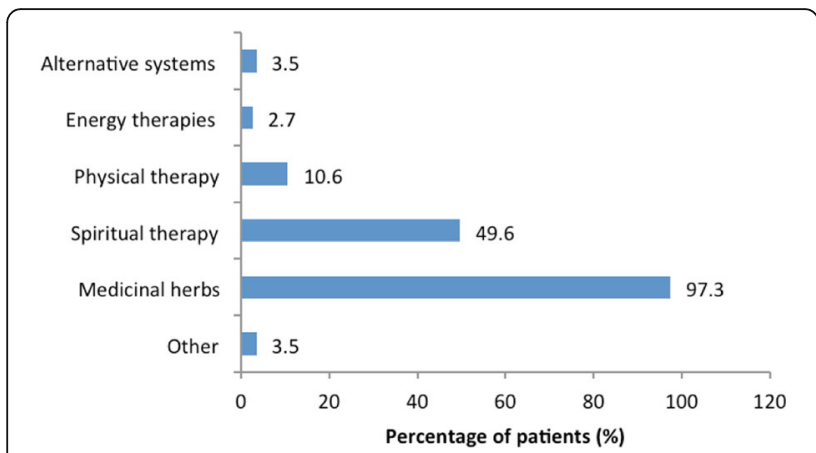

Fig. 1 Types of CAM therapy used by HIV patients $(n=130)$

at least one of these benefits, 13 of the 17 patients did not respond; 2 said they experienced increased energy, 1 said it assisted with sleep, and 1 said weight gain. Several patients gave reasons why they decided to use CAM (Table 5). The majority $(n=21,18.6 \%)$ of CAM users said they decided to use CAM because of their desire to try anything they thought would help improve their condition. Patients stated four specific benefits which they hoped to derive from CAM use: direct treatment of their condition ( $n=74,65.5 \%)$, enabling them to sleep ( $n=7$, $6.2 \%)$, relieve the symptoms/side effects associated with the use of CM ( $n=5,4.4 \%)$, and improvement of psychological well-being $(n=4,3.5 \%)$. Sixteen $(14.2 \%)$ patients did not respond. The majority $(n=86,76.1 \%)$ of CAM users were satisfied and 5 (4.4\%) were very satisfied.

Fifty-two (46\%) CAM users said that they did not know how to determine whether the type of CAM they were using was the right one. Others said the basis for using the right CAM resulted from book knowledge $(n=27,23.9 \%)$ or their CAM practitioner $(n=13$, $11.5 \%)$ (Fig. 2). Only 12 (10.6\%) users said that their use of CAM was supervised/guided by a healthcare provider (allopathic or CAM practitioner). When asked if they thought that the more knowledgeable a person is regarding CAM, the more likely he/she is to use it, $89(78.8 \%)$ agreed, 7 (6.2\%) agreed strongly, and only 9 (5.3\%) disagreed. The majority ( $n=32,32.7 \%$ ) learned about the type of CAM they were using from the mass media; and more users were informed by non-hospital health

Table 4 Frequency of medicinal herb/supplement intake among HIV patients who use CAM

\begin{tabular}{|c|c|c|c|}
\hline & Used in the past & Presently being used & Will use in the future \\
\hline Aloe vera (Aloe barbadensis Miller) & $54(47.8)$ & $51(45.1)$ & $54(47.8)$ \\
\hline Calcium & $34(30.1)$ & $35(31.0)$ & $33(29.2)$ \\
\hline Chinese herbal medicines & $7(6.2)$ & $7(6.2)$ & $8(7.1)$ \\
\hline Evening primrose & $8(7.1)$ & $8(7.1)$ & $9(8.0)$ \\
\hline Flaxseed & $14(12.4)$ & $14(12.4)$ & $15(13.3)$ \\
\hline Folic acid & $37(40.1)$ & $32(28.3)$ & $33(29.2)$ \\
\hline Ginger (Zingiber officinale) & $33(29.2)$ & $32(28.3)$ & $33(29.2)$ \\
\hline Gingko biloba & $40(35.4)$ & $40(35.4)$ & $42(37.2)$ \\
\hline Ginseng & $25(22.1)$ & $25(22.1)$ & $26(23.0)$ \\
\hline Potassium & $8(7.1)$ & $8(7.1)$ & $8(7.1)$ \\
\hline Turmeric & $8(7.1)$ & $8(7.1)$ & $7(6.2)$ \\
\hline Vitamin B complex & $69(61.1)$ & $70(61.9)$ & $70(61.9)$ \\
\hline Vitamin A & $57(50.4)$ & $57(50.4)$ & $58(51.3)$ \\
\hline Vitamin D & $42(37.2)$ & $42(37.2)$ & $43(38.1)$ \\
\hline Vitamin $\mathrm{E}$ & $51(45.1)$ & $51(45.1)$ & $51(45.1)$ \\
\hline Zinc & $17(15.0)$ & $17(15.0)$ & $18(15.9)$ \\
\hline Omega 3 & $20(17.7)$ & $23(20.4)$ & $22(19.5)$ \\
\hline Garlic (Allium sativum) & $23(20.4)$ & $23(20.4)$ & $23(20.4)$ \\
\hline Coenzyme Q10 & $3(2.7)$ & $3(2.7)$ & $3(2.7)$ \\
\hline Medicinal tea & $2(1.8)$ & $2(1.8)$ & $2(1.8)$ \\
\hline Sure Cure products & $14(12.4)$ & $13(11.5)$ & 13(11.5) \\
\hline Omega XL & $11(9.7)$ & $11(9.7)$ & $11(9.7)$ \\
\hline Special diet/supplements & $5(4.4)$ & $5(4.4)$ & $5(4.4)$ \\
\hline
\end{tabular}

CAM complementary and alternative medicine, HIV human immunodeficiency virus

Special diet/supplements: concoction of different products and/or food items to treat patient illness or to maintain wellness

Data are the mean number (percentage) 
Table 5 Reasons for deciding to use CAM

\begin{tabular}{lll}
\hline Reasons & Number & Percent \\
\hline The patient was disappointed that conventional treatment was not working & 7 & 6.2 \\
Conventional treatment was too toxic or damaging & 1 & 7 \\
CAM was more in keeping with personal beliefs and inner self & 10 & 0.9 \\
The patient felt the desire to take control of treatment & 0 & 0.2 \\
Conventional treatment was too mechanistic/technological and lacked human touch & 21 & 18.6 \\
The patient was just trying everything that could help & 2 \\
Conventional treatment was too expensive & 1.3 \\
\hline
\end{tabular}

personnel than by hospital health personnel $(19.5 \%$ vs. $0.9 \%$; $p \leq 0.001$ ) (Fig. 3).

Eight (7.1\%) CAM users said that they had seen an alternative medical practitioner prior to going to their medical doctor; 7 (6.2\%) mentioned to the doctor that they had used/were using CAM; and none of those who did not mention their use of CAM to their doctor stated why they were reluctant to do so. Only $11(9.7 \%)$ users expressed disappointment with CAM usage: 6(5.3\%) reported unwanted effects, namely acne $(n=1)$, redness $(n=1)$ and swelling $(n=1)$, and 3 were non-responses.

\section{Discussion}

In this study, the prevalence of CAM among HIV patients was $32.9 \%$. This is similar to the prevalence of 33.7\% among HIV patients in Uganda [43] but lower than that among HIV patients in Thailand (95\%) [44]. The more severe the chronic disease, the greater the likelihood of using CAM [45]. Terminal diseases are also associated with higher uses of CAM (a prevalence of $47.9 \%$ was reported in a study of cancer patients in Mongolia [46]). In this study, however, the prevalence of CAM among HIV patients was relatively lower. The relatively low prevalence of CAM use in Trinidad may also result from fear of using CAM along with antiretroviral drugs that have proven effective, and the lack of experience with CAM for HIV infection.

The use of CAM was more common among females $(58.4 \%)$ and young (21-40 years) patients (61.9\%). This is in

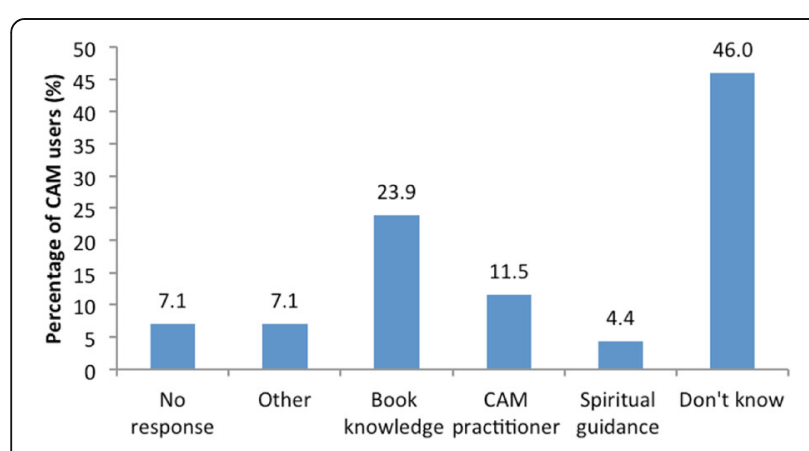

Fig. 2 Basis for choosing the right CAM therapy keeping with a review by Lorenc and Robinson, who found younger females were more likely to use CAM [47]. In our study, it was found that income was not associated with use of CAM as was found by Idung and Abasiubong [48]. In another study, female gender and higher income (greater than US\$250000 per year and higher literacy) [49] were associated with higher CAM usage. Education was also positively associated with CAM use [50]. This study reports higher use of CAM with secondary education compared with Primary school education.

CAM was more common among Indo-Trinidadians (59.8\%). Another study conducted among Africans (51.7\%), Caucasians (31.1\%), and Hispanics (13.7\%) reported that the majority of CAM users were of African descent [51]. Predictors of CAM among HIV patients revealed that the only predictors of CAM use among HIV patients were middle age, married and secondary school educated.

The majority of CAM users (97.3\%) used herbal medicines, the commonest being Aloe vera (49.1\%). This is of concern since many herbs are known for their toxic effects. Ginkgo biloba extract used by some patients has led to a virological breakthrough [52]. Though Aloe vera is fairly safe, there is still the possibility of drug interactions, including with antiretroviral drugs [53]. Spiritual therapy was also widely practiced, which is in agreement with the work by Cotton et al. [54] The majority of CAM users used at least one herb.

HIV drugs may also lead to side effects such as diarrhoea, nausea and vomiting, rashes, lipodystrophy, and

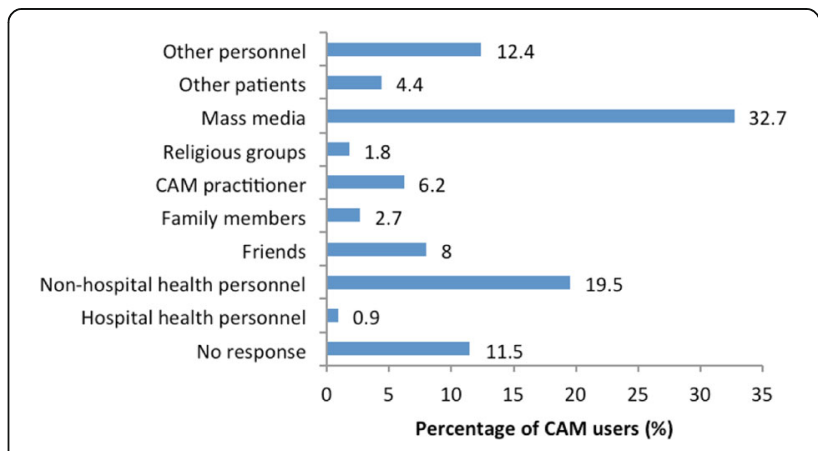

Fig. 3 Source of awareness about the type of CAM therapy used 
increased risk of heart attack. Antiretroviral drugs such as azidothymidine (AZT) may cause headaches and fatigue, stavudine (d4T) may cause peripheral neuropathy, protease inhibitors (PIs) may cause retinoid toxicity, and nonnucleoside reverse transcriptase inhibitors (NNRTIs) may cause hypersensitivity reactions [55].

The desire of patients to use CAM was attributed to their willingness to try anything. They hoped to treat the disease directly, improve sleep, relieve the symptoms/ side effects associated with the use of $\mathrm{CM}$, and improve psychological well-being. CAM usage is attributed to the increasing demand and expectations for more holistic and comprehensive care [6]. As previously reported by similar studies, people were discouraged by the inadequacy of $\mathrm{CM}$, mechanistic and lack of human touch of $\mathrm{CM}$, costly $\mathrm{CM}$, toxic $\mathrm{CM}$, and ineffective $\mathrm{CM}$ (push factors); and were encouraged by the synchrony with patients beliefs, the ability to take greater control of one's life and other CAM (pull factors). "Push" factors encompassed dissatisfaction with conventional treatments, whereas "pull" factors included a desire for more holistic and "natural" approaches, and a greater philosophical congruence with CAM [56]. CAM is regarded as being "natural" and "safe" [57], effective [58], and effective to reduce adverse effects [7]. CAM users also appreciate the feeling of control, coping, and adjustment [59].

The greatest influence for CAM usage came from the mass media (32.7\%), followed by non-hospital health personnel (19.5\%). Family members accounted for $2.7 \%$ only. This may reflect the limited extent of family and social support for these patients who end up relying on the mass media. A study in Bangkok on HIV/AIDS patients showed that the influence of friends (50.22\%), family (45.33\%), and health service providers (44.44\%) was much higher than in this study [59]. CAM usage also depends on the social, cultural, economic, and traditional influences [60]. Although there is the potential for major negative consequences, the majority of CAM users (76.1\%) were satisfied and a few (4.4\%) were very satisfied. This is in agreement with the high levels of satisfaction (69.2\%) found among HIV patients in a small cross-sectional study in India [61]. The majority of CAM users (88.5\%) refused to substitute $\mathrm{CM}$ by CAM. The failure to abandon $\mathrm{CM}$ reflects the continued value of $\mathrm{CM}$ and the desire to try something different to add value to their outcome.

Many patients $(46 \%)$ did not know if the type of CAM they were using was the right one although they became aware from sources such as books and their CAM practitioner. Furthermore, only $10.6 \%$ of CAM users were supervised/guided by a healthcare provider/professional. In fact, according to Wahner-Roedler et al., few doctors (24\%) are prepared to refer patients to a CAM practitioner [62]. In addition, doctors are unprepared to communicate and treat with CAM issues [63]. In this study, few healthcare providers $(6.2 \%)$ were informed about previous or present CAM usage. Another study reported that $76 \%$ were poorly informed about herbal medicines and $45.6 \%$ had "very poor" or "quite poor" knowledge of CAM. [64] Liu et al. [65] found that $36 \%$ of patients disclosed CAM practices to their physician. Furthermore, more than $77 \%$ of physicians do not discuss CAM treatments with their patients [66]. This may not be in the best interest of patient care since vital information required for the management of patients is lost. Nonetheless, even with the high nondisclosure rate found in this study, its use continues unregulated as a result of the lack of regulations in Trinidad and Tobago [67].

Low reporting to healthcare providers, high satisfaction rating with CAM usage and poor monitoring makes CAM a major public health problem. There are numerous herb-drug interactions [68] and lack of evidence in many cases to support their claims [8]. Major health consequences can result, including delayed treatment, disease complications, and occasionally death. CAM therapies are also of questionable safety and efficacy [69]. Public safety and a scientific basis for CAM usage have been emphasised by Trinidad and Tobago's Chief Medical Officer [70] and the World Health Organization (WHO) [71]. The simultaneous practice of CAM and $\mathrm{CM}$ needs greater understanding, communication, and integration of both. Policy makers, implementers, and customers need greater attention on CAM usage.

The limitations of this study include the selection of patients from a single HIV public clinic located at the SFGH in South Trinidad. The attendees of the clinic tended to be of a lower socioeconomic status and educational level, which is not fully representative of the population. There may be recall bias. To assist patient recall and to maintain uniformity on the meaning of CAM, patients were provided with a list of most common types of CAM and a list of options to choose from in various questions about CAM. The negative stigma attached to HIV patients is still felt by some and they may be reluctant to discuss their condition freely. To minimise negative feelings, patients were encouraged by the nurse and interviewed in private rooms in the clinic.

\section{Conclusions}

The prevalence of CAM use was relatively high (32.9\%) among HIV patients. The most used types of CAM were herbal therapy (97.3\%) and spiritual therapy (49.6\%). CAM usage was more common among young and female patients. Being of middle age, married, and secondary school educated were the only useful predictors of CAM use. Its use was driven by cost, individual beliefs, willingness to try anything, and perceived benefits such as wellbeing, relaxation, and counteracting the side effects of CM. The majority (over 90\%) of CAM users were satisfied 
with CAM. However, the majority are unwilling to disclose such information to their CM practitioners. HIV patients receive information mainly from the mass media and non-hospital health personnel. Non-disclosure, high satisfaction levels, and the simultaneous use of both CM and CAM make CAM practice a major public health problem because of the possibility of delayed treatment as well as herb-herb and herb-drug toxicity. Patients, the community, and CM and CAM practitioners need to have adequate information to guide patients in effective and appropriate usage, to minimise the risks of CAM, and to give greater empowerment to CAM users. This will also assist in providing safe and effective health care.

\section{Abbreviations \\ AZT: Azidothymidine; CAM: Complementary and alternative medicine; CM: Conventional medicine; CMO: Chief medical officer; d4T: Stavudine; HCP: Healthcare provider; HIV: Human immunodeficiency virus; NNRTI: Non- nucleoside reverse transcriptase inhibitor; PI: Protease inhibitor; SFGH: San Fernando General Hospital; WHO: World Health Organization}

\section{Acknowledgements}

I wish to acknowledge Dr. George Legall, statistician and lecturer at the University of the West Indies (Mt. Hope, Trinidad), who assisted with statistical analysis and methodology; Divya Maharaj, a premedical student who assisted with data collection; the staff at the HIV Department, who helped with the research; and the participants, who gave their time to enter the study.

\section{Funding}

Not applicable.

\section{Availability of data and materials}

The data that support the findings of this study are available from the corresponding author on request.

\section{Authors' contributions}

MB conceptualised, designed, conducted, and reviewed the study; and wrote and revised the manuscript.

\section{Authors' information}

MB is a Specialist Medical Officer and Consultant Physician at the San Fernando Hospital (San Fernando, Trinidad and Tobago) and a lecturer at the School of Medicine and Arthur Lok Jack Graduate School of Business at the University of the West Indies (Mt. Hope, Trinidad)

\section{Ethics approval and consent to participate}

This study received ethical approval from the Ethics Committee of SouthWest Regional Health Authority on 28th September 2014. All participants gave their consent to participate in the study.

\section{Consent for publication}

Not applicable.

\section{Competing interests}

The author declares no competing interests.

\section{Publisher's Note}

Springer Nature remains neutral with regard to jurisdictional claims in published maps and institutional affiliations.

\section{Author details}

'School of Medicine and Arthur Lok Jack Graduate School of Business, University of the West Indies, St. Augustine, Trinidad and Tobago. ${ }^{2}$ Department of Medicine, San Fernando General Hospital, Chancery Lane, San Fernando, Trinidad and Tobago. ${ }^{3}$ House \#57 LP 62, Calcutta Road Number 3, McBean, Couva, Trinidad, Trinidad and Tobago.
Received: 9 October 2016 Accepted: 15 August 2017

Published online: 23 August 2017

\section{References}

1. Chen RY, Accortt NA, Westfall AO, Mugavero MJ, Raper JL, Cloud GA, et al. Distribution of health care expenditures for HIV-infected patients. Clin Infect Dis. 2006:42:1003-10.

2. Mugavero MJ, Norton WE, Saag MS. Health care system and policy factors influencing engagement in HIV medical care: piecing together the fragments of a fractured health care delivery system. Clin Infect Dis. 2011;52 S238-46.

3. Fairfield KM, Eisenberg DM, Davis RB, Libman H, Phillips RS. Patterns of use, expenditures, and perceived efficacy of complementary and alternative therapies in HIV-infected patients. Arch Intern Med. 1998;158:2257-64.

4. Foote-Ardah CE. The meaning of complementary and alternative medicine practices among people with HIV in the United States: strategies for managing everyday life. Sociol Health IIIn. 2003;25:481-500.

5. Chinouya M, Davidson O. The Padare Project: assessing health-related knowledge, attitudes and behaviours of HIV-positive Africans accessing services in north central London. London: African HIV Policy Network; 2003.

6. Peltzer K, Preez NF, Ramlagan S, Fomundam $\mathrm{H}$. Use of traditional complementary and alternative medicine for HIV patients in KwaZulu-Natal. South Africa BMC Public Health. 2008:8:255.

7. Chen WT, Shiu CS, Simoni J, Fredriksen-Goldsen K, Zhang F, Starks H, et al. Attitudes toward antiretroviral therapy and complementary and alternative medicine in Chinese HIV-infected patients. J Assoc Nurses AIDS Care. 2009:20:203-17.

8. Littlewood RA, Vanable PA. Complementary and alternative medicine use among HIV+ people: research synthesis and implications for HIV care. AIDS Care. 2008;20:1002-18.

9. Tabish SA. Complementary and alternative healthcare: is it evidence-based? Int J Health Sci (Qassim). 2008:2:V-IX.

10. Zou W, Liu Y, Wang J, Li H, Liao X. Traditional Chinese herbal medicines for treating HIV infections and AIDS. Evid Based Complement Alternat Med. 2012;2012:950757

11. The Use of Complementary and Alternative Medicine in the United States. In: National Centre for Complementary and Integrative Health (NCCIH). 2008. https://nccih.nih.gov/research/statistics/2007/camsurvey_fs1. htm\#about. Accessed 18 Aug 2017.

12. Harris PE, Cooper KL, Relton C, Thomas KJ. Prevalence of complementary and alternative medicine (CAM) use by the general population: a systematic review and update. Int J ClinPract. 2012;66:924-39.

13. Barnes PM, Bloom B, Nahin RL. Complementary and alternative medicine use among adults and children: United States, 2007. Nati Health Stat Report; Number 12. 2008;(12):1-23. https://www.cdc.gov/nchs/data/nhsr/nhsr012. pdf. Accessed 16 Aug 2016.

14. Posadzki P, Watson LK, Alotaibi A, Ernst E. Prevalence of use of complementary and alternative medicine (CAM) by patients/consumers in the UK: systematic review of surveys. Clin Med. 2013:13:126-31.

15. Xue CC, Zhang AL, Lin V, Da Costa C, Story DF. Complementary and alternative medicine use in Australia: a national population-based survey. J Altern Complement Med. 2007;13:643-50.

16. Clement YN, Williams AF, Aranda D, Chase R, Watson N, Mohammed R, et al. Medicinal herb use among asthmatic patients attending a specialty care facility in Trinidad. BMC Complement Altern Med. 2005:5:3.

17. Bahall M. Complementary and alternative medicine usage among cardiac patients: a descriptive study. BMC Complement Altern Med. 2015;15:100

18. Mahabir D, Gulliford MC. Use of medicinal plants for diabetes in Trinidad and Tobago. Rev Panam Salud Publica. 1997;1:174-9.

19. Duggan J, Peterson WS, Schutz M, Khuder S, Charkraborty J. Use of complementary and alternative therapies in HIV-infected patients. AIDS Patient Care STDs. 2001;15:159-67.

20. Hsiao AF, Wong MD, Kanouse DE, Collins RL, Liu H, Andersen RM, et al. Complementary and alternative medicine use and substitution for conventional therapy by HIV-infected patients. J Acquir Immune Defic Syndr. 2003:33:157-65.

21. Payne-Jackson A, Alleyne MC. Jamaican folk medicine: a source of healing Barbados: The University of the West Indies Press; 2004

22. Clement Y. Limited clinical evidence to support the integration of Caribbean herbs into conventional medicine. Focus Altern Complement Ther. 2011;16:289-92. 
23. Frass $M$, Strassl RP, Friehs $H$, Müllner $M$, Kundi $M$, Kaye AD. Use and acceptance of complementary and alternative medicine among the general population and medical personnel: a systematic review. Ochsner J. 2012;12:45-56.

24. Moyne L, Stubbs R, Crowdy RE, Citrine W, Mackinnon P, Blacklock MG, et al. West India Royal Commission Report. London: Her Majesty's Stationery Office; 1945. (Command 6607)

25. Hsu C, Bluespruce J, Sherman K, Cherkin D. Unanticipated benefits of CAM therapies for back pain: an exploration of patient experiences. J Altern Complement Med. 2010;16:157-63.

26. Laptiste C, Beharry V, Edwards-Wescott P. A review of the response to HIV/ AIDS in Trinidad and Tobago: 1983-2010. Sahara J. 2013;10:72-82.

27. Basavaraj KH, Navya MA, Rashmi R. Quality of life in HIV/AIDS. Indian J Sex Transm Dis. 2010;31:75-80.

28. Ciesla JA, Roberts JE. Meta-analysis of the relationship between HIV infection and risk for depressive disorders. Am J Psychiatry. 2001;158:725-30.

29. Owe-Larsson B, Säll L, Salamon E, Allgulander C. HIV infection and psychiatric illness. Afr J Psychiatry (Johannesbg). 2009;12:115-28.

30. Kalichman SC, Heckman T, Kochman A, Sikkema K, Bergholte J. Depression and thoughts of suicide among middle-aged and older persons living with HIV-AIDS. Psychiatr Serv. 2000;51:903-7.

31. Ballester-Arnal R, Gómez-Martínez S, Fumaz CR, González-García M, Remor E, Fuster MJ. A Spanish study on psychological predictors of quality of life in people with HIV. AIDS Behav. 2016;20:281-91.

32. Turan JM, Bukusi EA, Onono M, Holzemer WL, Miller W, Cohen CR. HIV/AIDS stigma and refusal of HIV testing among pregnant women in rural Kenya: results from the MAMAS study. AIDS Behav. 2011;15:1111-20.

33. Dlamini PS, Kohi TW, Uys LR, Phetlhu RD, Chirwa ML, Naidoo JR, et al. Verbal and physical abuse and neglect as manifestations of HIV/AIDS stigma in five African countries. Public Health Nurs. 2007:24:389-99.

34. Current issues in HIV prevention. Interagency Coalition on Aids and Development. 2008. http://www.icad-cisd.com/pdf/Current_Issues_in_HIV_ Prevention_Final_EN.pdf. Accessed 12 Aug 2016.

35. Bachrach D, Pfister H, Wallis K, Lipson M. Addressing Patients' Social Needs: An Emergency Business Case for Provider Investment. The Commonwealth Fund, TheSkoll Foundation, The Pershing Square Foundation. 2014. http:// www.statecoverage.org/files/Manatt_Addressing_Patients_Social_Needs.pdf. Accessed 12 Mar 2017

36. Klitzman R. Doctors Fail to Address Patients' Spiritual Needs. The New York Times Company 2015. https://well.blogs.nytimes.com/2015/08/13/doctorsfail-to-address-patients-spiritual-needs/?_r=0. Accessed 12 Mar 2017

37. Rivera-Rodriguez AJ, Karsh B-T. Interruptions and distractions in healthcare review and reappraisal. Qual Saf Health Care. 2010;19:304-12.

38. Institute of Medicine. Crossing the Quality Chasm: a New Health System for the 21st Century. Washington, D.C.: National Academies Press; 2001.

39. Fraser M. HIV/AIDS: A growing concern. In: Trinidad Express Newspapers. 2013. http://www.trinidadexpress.com/featured-news/HIVAIDS\%2D-Agrowing\%2D-concern-237913291.html. Accessed 7 Jul 2015.

40. May MT, Gompels M, Delpech V, Porter K, Orkin C, Kegg S, et al. Impact on life expectancy of HIV-1 positive individuals of CD4+ cell count and viral load response to antiretroviral therapy. AIDS. 2014;28:1193-202.

41. South West Regional Health Authority: Facilities. SWRHA. 2017. http://www. swrha.co.tt/content/about-swrha. Accessed 18 Aug 2017.

42. Lwanga SK, Lemeshow S. Sample Size Determination in Health Studies: A Practical Manual. World Health Organization; Geneva 1991. http://apps.who.int iris/bitstream/10665/40062/1/9241544058_(p1-p22).pdf. Accessed 10 Mar 2017.

43. Namuddu B, Kalyango JN, Karamagi C, Mudiope P, Sumba S, Kalende H, et al. Prevalence and factors associated with traditional herbal medicine use among patients on highly active antiretroviral therapy in Uganda. BMC Public Health. 2011;11:855.

44. Wiwanitkit $\mathrm{V}$. The use of CAM by HIV-positive patients in Thailand. Complement Ther Med. 2003;11:39-41.

45. Falci L, Shi Z, Greenlee H. Multiple chronic conditions and use of complementary and alternative medicine among US adults: Results from the 2012 National Health Interview Survey. Prev Chronic Dis. 2016;13:150501.

46. Oyunchimeg B, Hwang JH, Ahmed M, Choi S, Han D. Complementary and alternative medicine use among patients with cancer in Mongolia: a National hospital survey. BMC Complement Altern Med. 2017;17:58.

47. Lorenc A, Robinson N. A review of the use of complementary and alternative medicine and HIV: Issues for patient care. AIDS Patient Care STDs. 2013;27:503-10.
48. Idung AU, Abasiubong F. Complementary and alternative medicine use among HIV-infected patient's on anti-retroviral therapy in the Niger Delta Region. Nigeria Clin Med Res. 2014;3:153-8.

49. Owen-Smith A, McCarty F, Hankerson-Dyson D, DiClemente R. Prevalence and predictors of complementary and alternative medicine use in AfricanAmerians with acquired immune deficiency syndrome. Focus Altern Complement Ther. 2012;17:33-42.

50. Abou-Rizk J, Alameddine M, Naja F. Prevalence and characteristics of CAM use among people living with HIV and AIDS in Lebanon: Implications for patient care. Evid Based Complement Alternat Med. 2016;2016:5013132.

51. Josephs JS, Fleishman JA, Gaist P, Gebo KA. HIV Research Network. Use of complementary and alternative medicines among a multistate, multisite cohort of people living with HIV/AIDS. HIV Med. 2007:8:300-5.

52. Naccarato M, Yoong D, Gough K. A potential drug-herbal interaction between Ginkgo biloba and efavirenz. J Int Assoc Physicians AIDS Care (Chic). 2012;11:98-100

53. Mayo Clinic. Drugs and supplements. 1998-2017 Mayo Foundation for Medical Education and Research (MFMER) http://www.mayoclinic.org/drugssupplements. Accessed 06 Mar 2017.

54. Cotton S, Puchalski CM, Sherman SN, Mrus JM, Peterman AH, Feinberg J, et al. Spirituality and religion in patients with HIV/AIDS. J Gen Intern Med. 2006;21:S5-13.

55. Montessori $\mathrm{V}$, Press $\mathrm{N}$, Harris M, Akagi L, Montaner J. Adverse effects of antiretroviral therapy for HIV infection. CMAJ. 2004;170:229-38.

56. Nichol J, Thompson EA, Shaw A. Beliefs, decision-making, and dialogue about complementary and alternative medicine (CAM) within families using CAM: a qualitative study. J Altern Complement Med. 2011:17:117-25.

57. Orisatoki RO, Oguntibeju OO. The role of herbal medicine use in HIV/AIDS treatment. AC Microb. 2010;1:3.

58. Langlois-Klassen D, Kipp W, Jhangri GS, Rubaale T. Use of traditional herbal medicine by AIDS patients in Kabarole District, Western Uganda. Am J Trop Med Hyg. 2007;77:757-63.

59. Limsatchapanich S, Sillabutra J, Nicharojana LO. Factors related to the use of complementary and alternative medicine among people living with HIV/ AIDS in Bangkok. Thailand Health Sci J. 2013;7:436-46.

60. Hussain S, Malik F. Integration of complementary and traditional medicines in public health care systems: challenges and methodology. J Med Plant Res. 2013;7:2952-9.

61. Mayo Clinic Staff. Complementary and alternative medicine: evaluate claims. In: Healthy Lifestyle. Mayo Clinic. 2014. http://www.mayoclinic.org/healthylifestyle/consumer-health/in-depth/alternative-medicine/art-20046087. Accessed 20 May 2015.

62. Wahner-Roedler DL, Vincent A, Elkin PL, Loehrer LL, Cha SS, Bauer BA. Physicians' attitudes toward complementary and alternative medicine and their knowledge of specific therapies: A survey at an academic medical center. Evid Based Complement Alternat Med. 2006;3:495-501.

63. Bahall M, Legall G. Knowledge, attitudes, and practices among health care providers regarding complementary and alternative medicine in Trinidad and Tobago. BMC Complement Altern Med. 2017:17:144

64. HealthDay. Most doctors not knowledgeable about herbals. Modern Medicine Network. 2010. www.modernmedicine.com/modernmedicine/ Modern+Medicine+Now/Most-Doctors-Not-Knowledgeable-About-Herbals/ ArticleNewsFeed/Article/detail/666928. Accessed 12 Mar 2017.

65. Liu C, Yang Y, Gange SJ, Weber K, Sharp GB, Wilson TE, et al. Disclosure of complementary and alternative medicine use to health care providers among HIV-infected women. AIDS Patient Care STDs. 2009:23:965-71.

66. Robinson A, McGrail MR. Disclosure of CAM use to medical practitioners: a review of qualitative and quantitative studies. Complement Ther Med. 2004;12:90-8.

67. Gordon Z. Health Minister: laws coming to regulate herbal business. In: Guardian. 2012. https://guardian.co.tt/news/2012-05-16/health-minister-lawscoming-regulate-herbal-business. Accessed 26 Feb 2015.

68. Tachijan A, Maria V, Jahangir A. Use of herbal products and potential interactions in patients with cardiovascular diseases. J Am Coll Cardiol. 2010;55:515-25.

69. Lee LS, Andrade AS, Flexner C. Interactions between natural health products and antiretroviral drugs: pharmacokinetic and pharmacodynamic effects. Clin Infect Dis. 2006:43:1052-9.

70. Baldeosingh K. Cracking down on alternative medicine. In: Trinidad Express. 2010. http://www.trinidadexpress.com/news/Cracking_down_on alternative_medicine-104222959.html. Accessed 26 Feb 2015.

71. Bodeker G, Kronenberg F. A public health agenda for traditional, complementary, and alternative medicine. Am J Public Health. 2002;92:1582-91. 